\title{
Evaluation of facial soft tissues by stereophotogrammetry method in patients with obstructive sleep apnoea: a morphological study
}

\author{
B. Karadede Ünal@ 1 , C. Hüseyin $(1)$ \\ Department of Orthodontics, Faculty of Dentistry, Izmir Katip Çelebi University, Izmir, Turkey
}

[Received: 18 February 2021; Accepted: 8 March 2021]

\begin{abstract}
Background: We aimed to use the "SomnoMed MAS" device, which brings the mandible forward in obstructive sleep apnoea syndrome patients due to mandibular retrognathia, and to examine its effects on facial soft tissues by stereophotogrammetry (3dMD) method.

Materials and methods: Thirty-one patients with a mean age of 44 years and 6 months were included in the study. SomnoMed MAS, one of the splint appliances that position the mandible in front, was applied to all patients and the changes in facial soft tissues were examined by overlapping the images taken at different times with the 3dMD face system. The obtained data were analysed statistically and the level of statistical significance was determined as $p \leq 0.05$.

Results: Mouth width decreased statistically during TO-T1 period. In TO-T2 period, while crista philtri and labiale inferius points moved backwards, Mouth width, nose width decreased and nasal base width increased. In the TO-T3 period, nasal base width increased statistically, the philtrum width and the mouth width decreased, and the soft tissue nasion point came to the fore.

Conclusions: Splint treatment, which positions the mandible in front in adult obstructive sleep apnoea syndrome patients, affected the middle and lower facial soft tissues with the forward and downward translational movement of the lower jaw. (Folia Morphol 2021; 80, 2: 432-441)
\end{abstract}

Key words: appliances, obstructive sleep apnoea syndrome, stereophotogrammetry, snoring

\section{INTRODUCTION}

Obstructive sleep apnoea syndrome (OSAS) is defined as the involuntary blockage of breathing that lasts at least 10 seconds or more with a decrease in oxygen saturation in the blood due to collapse of the upper respiratory tract at varying degrees while breathing during sleep [13]. One of the most prominent features of OSAS is snoring. However, not every snoring patient should be diagnosed with OSAS. Snoring increases due to fat accumulation in obese patients with OSAS. Sleeping position affects the severity of these symptoms [19]. OSAS characterised by recurrent partial or complete upper airway obstructions that develop during sleep in patients. More than $75 \%$ of OSAS patients have airway collapse in the velopharyngeal/retropalatal region $[8,21]$.

Address for correspondence: Dr. B. Karadede Ünal, İzmir Katip Çelebi Üniversitesi Diş Hekimliği Fakültesi, Aydınlıkevler Mahallesi, Cemil Meriç Bulvarı, 6780 Sokak. No: 48, Çiğli, İzmir, Turkey, Address code: 1537976407, Post code: 35640, tel: +90 (232) 3254040 , fax: +90 (232) 32525 25, e-mail: dtbeyzaunalkaradede@gmail.com

This article is available in open access under Creative Common Attribution-Non-Commercial-No Derivatives 4.0 International (CC BY-NC-ND 4.0) license, allowing to download articles and share them with others as long as they credit the authors and the publisher, but without permission to change them in any way or use them commercially. 
The traditional important diagnostic method of OSAS is the overnight polysomnography (PSG) test performed in sleep laboratories $[14,30]$. In addition to sleep stages, many physiological parameters, functions of different organs, and their interactions during sleep and wakefulness are examined with PSG [3]. If the number of apnoeas observed in an hour of sleep is less than 5, simple snoring is mentioned, if 5-15 is mild, 15-30 is moderate, and if it is 30 or more, it is mentioned that there is severe sleep apnoea syndrome $[23,30]$. The third edition of the International Classification of Sleep Disorders defines obstructive sleep apnoea (OSA) as a PSG-determined obstructive respiratory disturbance index (RDI) $\geq 5$ events per hour associated with the typical symptoms of OSA (e.g., unrefreshing sleep, daytime sleepiness, fatigue or insomnia, awakening with a gasping or choking sensation, loud snoring, or witnessed apnoeas), or an obstructive RDI more than 15 events per hour (even in the absence of symptoms) [15].

The most commonly used method for the treatment of OSAS disease is the use of a continuous positive nasal airway pressure (nCPAP) device. It is thought that the positive changes achieved with the use of this device are the result of a decrease in upper airway oedema [28]. Continuous positive airway pressure provides a stable positive pressure across inspiration and expiration [30]. Tracheostomy, nasal septal surgery, hyoid bone suspension, partial tongue resection, mandibular surgery, maxillomandibular advancement osteotomy, inferior mandibular osteotomy, lingualplasty, hyoid myotomy and suspension combined with genioglossal advancement, laser uvuloplasty, uvulopalatopharingoplasty methods are surgical treatment approaches of OSAS $[7,18]$. Some authors recommend that sleep physicians can consider prescription of oral appliances, rather than no treatment, for adult patients with OSA who are intolerant of CPAP therapy or prefer alternate therapy [24]. Oral devices are used in patients who cannot tolerate nCPAP therapy, who cannot undergo surgery due to their systemic condition and who are diagnosed with mild and mild-moderate sleep apnoea as a result of the PSG test. With these devices, only OSA can be treated, but central and mixed apnoeas cannot be treated [13].

The appliances that position the mandible in front and the devices which have tongue retainer feature prevent retroglossal collapse. The importance of minor tooth movements and small changes in occlusion during the use of these appliances is controversial [32]. Most important advantages of the intraoral devices are easily tolerated, non-invasive, reversible method, cheap, less patient time in the clinic, available for patients with or without teeth, are easy to carry, the use of the appliance does not affect daily life, is physiologically harmless, does not dissolve in water and is odourless [5].

Although there are studies investigating the effects of intraoral appliances used by sleep apnoea patients on the teeth and skeletal system, we have not come across a study that investigates the effect on facial soft tissues in a comprehensive way. In order to shed light on the unknowns in this field, we aimed to use the "SomnoMed MAS" device, which brings the lower jaw forward in OSAS patients due to mandibular retrognathia [4], and to examine its effects on facial soft tissues by stereophotogrammetry method including anatomical landmarks. This appliance is custom-made two-piece MAS (SomnoDent MAS, SomnoMed, Crows Nest, Australia) device. This appliance positions the lower jaw at the front as a result of the wings in the lower part sitting on the front of the upper part with the logic of the functional appliance [20]. Three-dimensional (3D) stereophotogrammetry method is safe, noninvasive and able to capture superior quality 'external surface' 3D photographs in less than $10 \mathrm{~ms}$ [20].

\section{MATERIALS AND METHODS}

\section{Patient follow-up}

This study was conducted on patients diagnosed with OSAS in sleep clinics, in the Department of Orthodontics, Faculty of Dentistry of Izmir Katip Celebi University. In this study, G * Power 3.1 software programme (Franz Foul, Universität Kiel, Germany) was used to determine the sample size. It was seen that 30 patients would be sufficient for this study, and a total of 31 individuals, 20 men and 11 women, with an average age of 44 years and 6 months (19 years 10 months-60 years) were included in the study. SomnoMed MAS (SomnoDent MAS, SomnoMed Ltd, Australia), one of the types of mandibular repositioner apparatus for therapeutic purposes, was applied to these patients. The approval of the ethics committee dated 07.06.2018 and numbered 68 was obtained 
from Izmir Katip Celebi University Interventional Clinical Research Ethics Committee.

Inclusion criteria of the individuals were as follows:

- patients between the ages of 19-60, with mandibular retrognathia and sleep apnoea syndrome;

- having enough teeth and retention areas to apply the apparatus;

- good oral hygiene;

- absence of temporomandibular joint problems;

- absence of severe skeletal malocclusion, systemic disease and no history of operation in the head and neck region;

- not having orthodontic or orthognathic treatment.

The exclusion criteria of the individuals are as follows:

- patients not complying with the treatment protocol;

- not paying attention to oral hygiene.

Upper and lower impressions were taken from individuals. For the standardisation of the forward activation of the lower jaw in the sagittal direction, a wax was used to register a protrusive bite by $75 \%$ of the maximum amount of protrusion [9].

Facial soft tissues of patients was performed immediately before the appliance is applied (T0), after 1 hour of use (T1), 3 days (T2), and after 8 hours of use while sleeping at night for 7 days (T3) with the 3D imaging system (3dMD, Atlanta, Ga, USA). In the study, an in-group evaluation was made and the TO group was used as the control group.

The analysis of the images obtained by the stereophotogrammetry method was made with the $3 \mathrm{dMD}$ Vultus analysis programme (3dMD, Atlanta, Ga, USA). Images were overlapped in order to measure point and volumetric changes in the records (Figs. 1-3). As stated Maal et al. [20], the forehead, nasal dorsum and temple areas were used to overlap. The registration process has been applied in such a way that the root mean square (RMS) value reaches the lowest possible value [29].

\section{Statistical analysis}

The data were evaluated in the IBM SPSS Statistics Standard Concurrent User V 25 (IBM Corp., Armonk, New York, USA) statistical package program. Descriptive statistics are given as unit number $(n)$, percentage $(\%)$, mean \pm standard deviation $(x \pm S D)$ values. Normality of measurement difference was evaluated by Shapiro-Wilk normality test and Q-Q charts. Before and after treatment measurement differences were compared with paired $t$ test. A value of $p<0.05$ was considered statistically significant.

\section{Ethical committee approval and informed consent}

The study protocol was approved by the Health Research Ethics Board of Izmir Katip Çelebi University, School of Medicine, a report of ethics committee decision numbered 68 and dated June, 7, 2018. The study was conducted in accordance with the principles of the Declaration of Helsinki. In this research, conebeam computed tomography (CT) images, which was previously recorded for diagnostic and therapeutic purposes, was used from the archives of Izmir Katip Çelebi University Faculty of Dentistry Department of Radiology.

A written informed consent was obtained from each participant.

\section{RESULTS}

Images were taken from the individuals included in the study at the TO, T1, T2 and T3 periods and the differences were determined by overlapping them. Looking at the point values in Table 1, alare right and cheilion left points came to the fore statistically significantly in the T0-T1 period. In the T0-T2 period, crista philtri right, crista philtri left and labiale inferius points moved back statistically significantly. Soft tissue nasion and alare right points came to the fore significantly in the T0-T3 period $(p<0.05)$.

Looking at the linear measurements, a statistically significant decrease was observed in the mouth width in all three periods. In the T0-T2 period, while the nose width decreased, the nasal base width increased. In the T0-T3 period, while the philtrum width decreased, the nasal base width increased statistically $(p<0.05)$ (Table 2).

When the volumetric, proportional and angular parameters are examined, no statistically significant change was observed in any of the T0-T1, T0-T2 and T0-T3 periods $(p>0.05)$. The changes in the total face volume values, the upper facial volume and lower facial volume were not statistically significant at the T0-T1, T0-T2 and T0-T3 periods. In addition, we evaluated the ratio of the results obtained from the measurements we made in our study. There was no statistically significant difference in the ratio of 


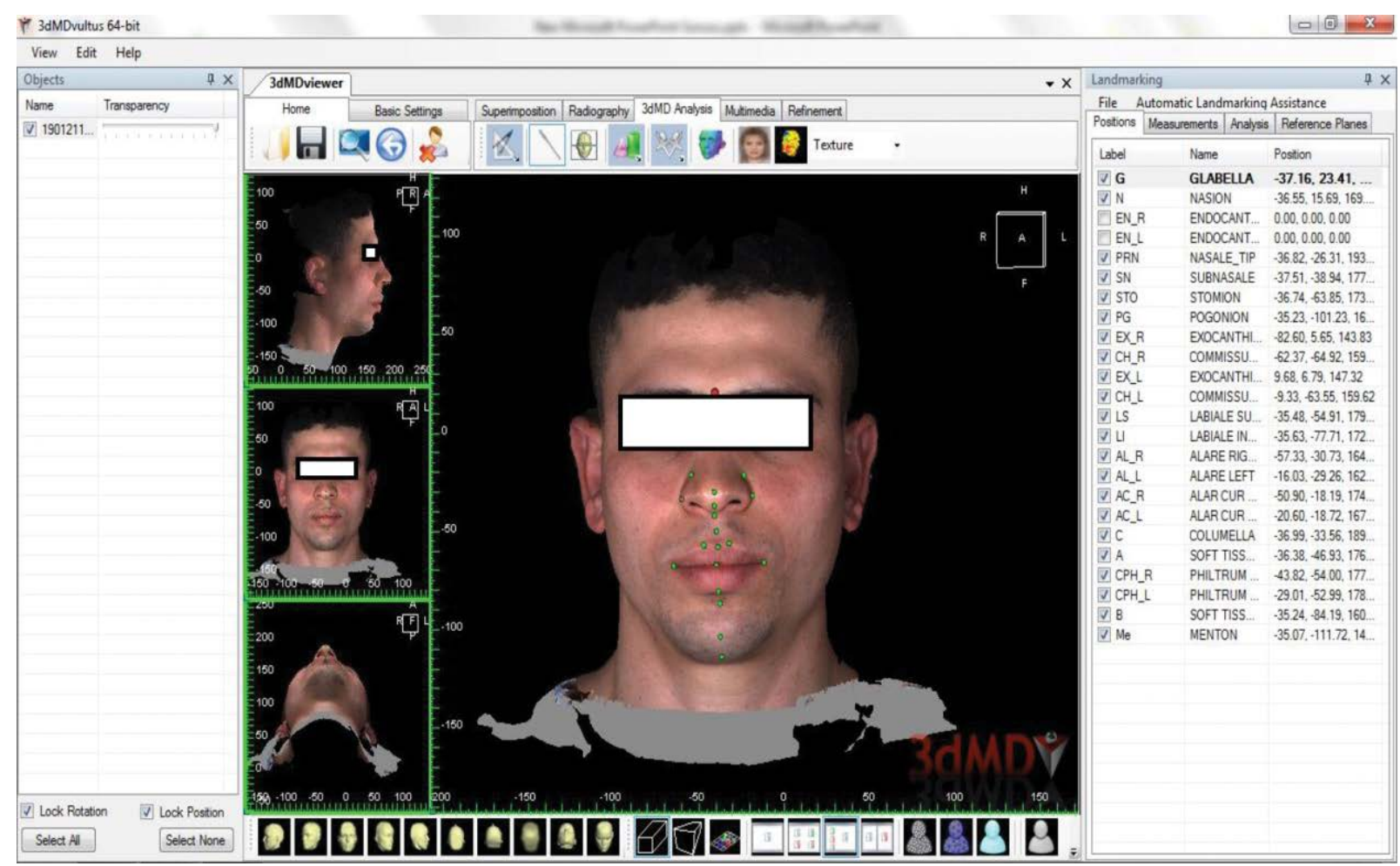

Figure 1. Points used in the analysis of three-dimensional face scan image data. 1) Glabella point (G'): It is the most anterior midpoint of the fronto-orbital soft tissue contour; 2) Soft tissue nasion point ( $\left.\mathbf{N}^{\prime}\right)$ : It is the most posterior point of the nasal root in the soft tissue contour; 3) Exocanthion (exr, exI): It is the outer edge point of both eyeballs; 4) Pronasale point (Prn'): It is the most anterior point of the tip of the nose. If there is a bifid nasal structure, the most anterior point should be chosen; 5) Subnasale point (Sn'): It is the point on the nasolabial soft tissue contour of the junction of columella and upper lip; 6) Alare points (Alr, All): The outermost points of both alar curvatures; 7) Alar curvature points (Acr, Acl): The junction points of both alar bases with the facial structure; 8) Columella point (C'): It is the midpoint of Columella at the nostril top point level; 9 ) Soft tissue $\mathbf{A}$ point $\left(\mathbf{A}^{\prime}\right)$ : It is the deepest point of philtrum; 10) Labiale superius point (Ls): It is the midpoint of the upper lip on the vermillion line; 11) Crista philtri points (Cphr, Cphl): They are the junction points of the vermillion line and the upward edges of the philtrum; 12) Stomion point (Sto): It is the horizontal midpoint of the joint of the two lips when the lips are closed. If the lips do not close when the patient is in the resting position, it is the point in the middle of the gap between the lips; 13) Cheilion points (Chr, Chl): They are the edge joints of the lips; 14) Labiale inferius point (Li): It is the midpoint of the lower lip on the vermillion line; 15) Soft tissue B point (B'): It is the deepest point of the labiomental soft tissue contour between the lower lip and the tip of the chin; 16) Soft tissue pogonion point (Pog'): It is the outermost point of the chin tip; 17) Soft tissue menton point (Me'): It is the lowest point of the soft tissue contour of the chin tip. It corresponds to the projection of the skeletal menton point.

philtrum length to mouth width, the ratio of mouth width/total vermillion length, upper lip length/lower lip length, the ratio of upper lip vermillion length/ lower lip vermillion length, and the ratio of anterior facial height/lower facial height at the T0-T1, T0-T2, and T0-T3 periods.

Some important angular measurements were also made on soft tissues in our study. Interlabial angle, the lower lip angle, and upper lip angle did not change statistically significant at the T0-T1, T0-T2, and TO-T3 stages. Similarly, we found that the nasomental angle, labiomental angle, nasolabial angle and nasofrontal angle did not show statistically significant changes in the T0-T1, T0-T2 and T0-T3 stages.
There were no statistically significant differences in the soft tissue convexity angle at the T0-T1, T0-T2, and TO-T3 periods.

\section{DISCUSSION}

There are various mandibular advancement appliances used in the treatment of OSAS patients [12]. Among the reasons we prefer the SomnoMed MAS device, which positions the mandible for 8 hours at night for all patients with OSAS, the sagittal screws placed in the upper part can be activated in the sagittal direction when necessary, the outer part of the apparatus is made of rigid acrylic that wraps all teeth rigidly and increases stabilisation, since the inner 


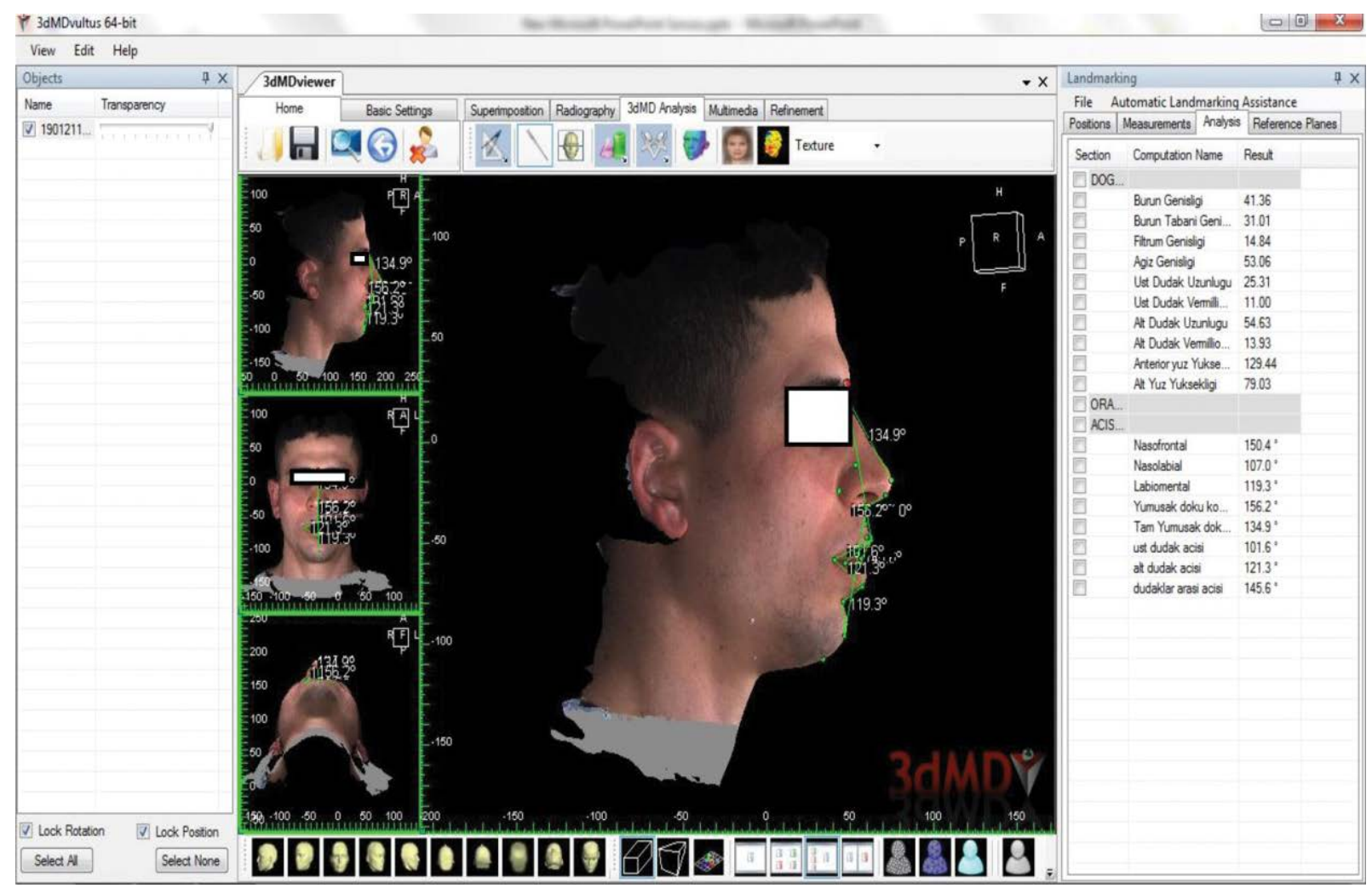

Figure 2. Linear, proportional and angular measurements used on three-dimensional face scan images. Linear measurements: 1) Nasal width (Alr-All): It is the distance between the outermost points of the right and left nasal wings; 2) Nasal base width (Acr-Acl): It is the distance between the right and left alar base; 3) Philtrum width (Cphr-Cphl): It is the distance between right and left crista philtri points; 4) Mouth width (Chr-Chl): It is the distance between the right and left angles of the mouth; 5) Upper lip length (Sn'-Sto): It is the distance between the subnasale and stomion points; 6) Upper lip vermillion length (Ls-Sto): It is the distance between labiale superius and stomion points; 7) Lower lip length (Sto-Me'): The distance between the stomion and soft tissue menton points; 8) Lower lip vermillion length (Sto-Li): It is the distance between stomion and labiale inferius points; 9) Anterior face height ( $\left.\mathbf{N}^{\prime}-\mathbf{M e}^{\prime}\right)$ : It is the distance between soft tissue nasion and soft tissue menton points; 10) Lower face height ( $\left.\mathbf{S n}^{\prime}-\mathbf{M e}^{\prime}\right)$ : The distance between the subnasale and soft tissue menton points; Proportional measurements: 1) N'-Me'/Sn'-Me': It is the ratio of the height of the anterior face to the height of the lower face; 2) Ls-Sto/Sto-Li: It is the ratio of the vermillion length of the upper lip to the vermillion length of the lower lip; 3) Sn'-Sto/Sto-Me': It is the ratio of the length of the upper lip to the length of the lower lip; 4) Chr-Chl/Ls-Li: It is the ratio of mouth width to total vermillion length; 5) Cphr-Cphl/Chr-Chl: It is the ratio of the philtrum width to the mouth width; Angular measurements: 1) Nasofrontal angle (G'-N'-Prn'): It is the angle between the soft tissue glabella, nasion and pronasale points; 2 ) Nasolabial angle (C'-Sn'-Ls): It is the angle between the soft tissue columella, subnasale and labiale superius points; 3) Labiomental angle (Li-B'-Pog'): It is the angle between the labiale inferius, soft tissue $B$ and soft tissue pogonion points; 4) Soft tissue convexity angle ( $\left.\mathbf{N}^{\prime}-\mathbf{S n}^{\prime}-\mathbf{P o g}^{\prime}\right)$ : It is the angle between the soft tissue nasion, subnasale and soft tissue pogonion points; 5) Nasomental angle ( $\left.\mathbf{N}^{\prime}-\mathbf{P r n}^{\prime}-\mathbf{P o g}^{\prime}\right)$ : It is the angle between the soft tissue nasion, pronasale and soft tissue pogonion points; 6) Upper lip angle (Chr-Ls-Chl): It is the angle between the right cheilion, labiale superius and left cheilion points;

7) Lower lip angle (Chr-Li-Chl): It is the angle between the right cheilion, labiale inferius and left cheilion points; 8) Interlabial angle (Ls-Sto-Li): It is the angle between labiale superius, stomion and labiale inferius points.

part covering the teeth is made of soft material, it causes less discomfort to the patients, patients can use this device without the need of a physician and also allows jaw movements because the upper and lower parts are separate.

Arnett et al. [1] stated that the changes in facial soft tissues were completed at the age of 12 in girls, and that growth continued until the age of 17 in boys. In our study, individuals with an average age of 44 years and 6 months were included in the study. Due to the disadvantages of two-dimensional (2D) imaging methods, 3D CT method, which is a more sensitive method, has been widely used [27]. There are a number of limitations of CT systems. The images captured on the detector screens are made up of multiple slices that are 'stacked' to obtain a final complete image. Furthermore, the radiation exposure to the patient has limited its usage to complex 


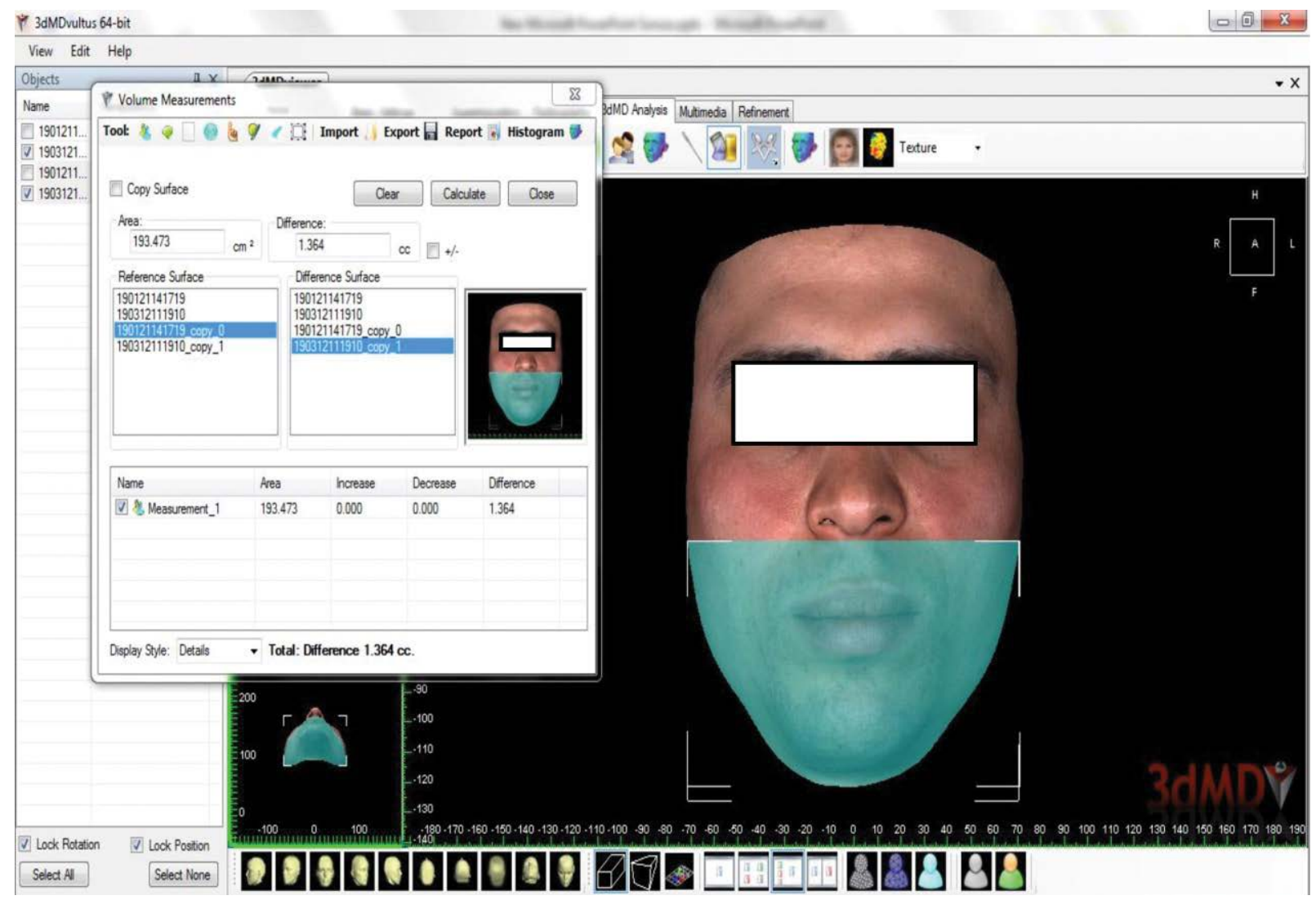

Figure 3. Calculation of volumetric measurements; 1 ) Total facial volume: It covers the area from the soft tissue nasion ( $\mathrm{N}^{\prime}$ ) point on the top to the soft tissue pogonion ( $\left.\mathrm{Pog}^{\prime}\right)$ point at the bottom; 2) Upper face volume: It covers the area from the upper soft tissue nasion ( $\left.\mathrm{N}^{\prime}\right)$ point to the lower subnasale (Sn) point; 3 ) Lower face volume: It covers the region from the subnasale (Sn) point at the top to the soft tissue pogonion (Pog') point at the bottom.

Table 1. Point changes obtained from image registration and statistical evaluation results

\begin{tabular}{|c|c|c|c|c|c|c|c|c|c|}
\hline \multirow[t]{2}{*}{ Parameters } & \multicolumn{3}{|c|}{ T0-T1 } & \multicolumn{3}{|c|}{ TO-T2 } & \multicolumn{3}{|c|}{ TO-T3 } \\
\hline & $X$ diff. [mm] & SD & $\mathbf{P}$ & $X$ diff. [mm] & SD & $\mathbf{P}$ & $X$ diff. [mm] & SD & $\mathbf{P}$ \\
\hline Soft tissue nasion (N') & -0.0729 & 0.49013 & 0.414 & 0.1019 & 0.39049 & 0.156 & 0.1916 & 0.45360 & $0.025 *$ \\
\hline Alare right (Alr) & 0.1668 & 0.37818 & $0.020^{*}$ & 0.0916 & 0.34294 & 0.147 & 0.1448 & 0.33430 & $0.022 *$ \\
\hline Crista philtri right (Cphr) & -0.1623 & 0.84917 & 0.296 & -0.3929 & 0.97084 & $0.032^{*}$ & -0.1210 & 0.83410 & 0.426 \\
\hline Crista philtri left (Cphl) & -0.2119 & 0.81224 & 0.157 & -0.3368 & 0.84081 & $0.033^{*}$ & -0.0665 & 0.81022 & 0.651 \\
\hline Cheilion left (Chl) & 0.3910 & 0.98621 & $0.035^{*}$ & 0.0426 & 0.95294 & 0.805 & 0.0481 & 1.02750 & 0.796 \\
\hline Labiale inferius (Li) & -0.2197 & 1.02785 & 0.243 & -0.5761 & 1.11018 & $0.007^{*}$ & -0.3145 & 1.15843 & 0.141 \\
\hline
\end{tabular}

${ }^{*}$ Statistically significant $(p<0.05)$, standard deviation $(S D)$, mean $(x)$

craniofacial problems and for specialised diagnostic information only. Magnetic resonance imaging has been shown to be useful in a variety of head and neck applications and is a relatively safe but costly procedure. It has been applied to the analysis of tem- poro-mandibular joints, preoperative planning of tumour resection and maxillary sinus evaluation [16]. Magnetic resonance imaging can assess soft tissue size but this method is expensive and has relatively poor resolution for surface changes. Ideally, the 


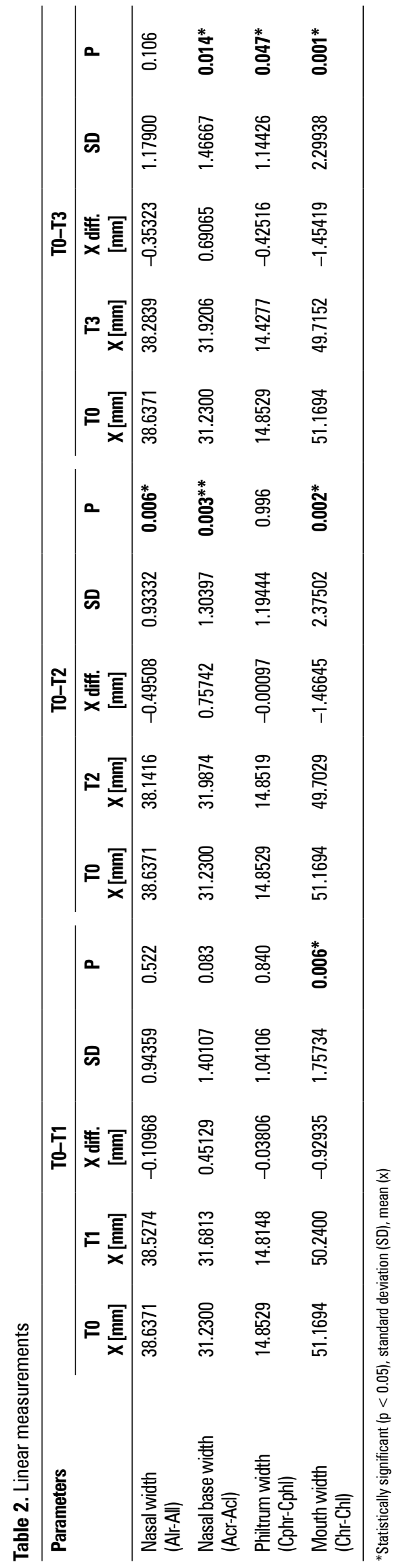

quantitative assessment of the main characteristics of the human face should be a 3D evaluation. One such objective and quantitative method for analysing facial dimensions is 3D stereophotogrammetry system. This system uses two digital camera pods to create a 3D facial image [26]. The development of the stereophotogrammetry method has made a breakthrough in the examination of facial soft tissues. Lin et al. [17] compared these methods by taking $\mathrm{CT}, 3 \mathrm{dMD}$, and $2 \mathrm{D}$ photograph from 38 patients diagnosed with OSA. They found that the records obtained by $3 \mathrm{dMD}$ and $\mathrm{CT}$ methods were compatible with OSA severity.

Maal et al. [20] determined variations in the face at rest; $1003 \mathrm{dMD}$ photographs of the same individual were acquired at different times. Initially, $503 \mathrm{dMD}$ photographs were obtained; 25 using a wax bite to ensure similar occlusion between subsequent photographs and 25 without wax bite. This procedure was repeated 6 weeks later. Variation of the face at rest was computed. The mean error of the system (RMS) of all four groups ranged from $0.21 \mathrm{~mm}$ to $0.27 \mathrm{~mm}$. The standard deviation ranged from $0.20 \mathrm{~mm}$ to $0.26 \mathrm{~mm}$. The results for the different anatomical regions are illustrated in Table 2. The RMS error ranged from $0.16 \mathrm{~mm}$ to $0.37 \mathrm{~mm}$. The $90^{\text {th }}$ percentile error ranged from $0.33 \mathrm{~mm}$ to $0.78 \mathrm{~mm}$ and the $95^{\text {th }}$ percentile error ranged from $0.40 \mathrm{~mm}$ to $1.01 \mathrm{~mm}$. The values in our study were also compatible with this study. This shows the reliability of the method used.

The methodology used by Maal et al. [20] for the forehead, nose and temple areas was also applied in this study. The points, planes, angular and volumetric parameters selected in the measurements are compatible with the parameters on soft tissues in 3D of other studies [6, 10, 22, 31]. Hammond et al. [11] used the splint, which positions the mandible anteriorly in 64 patients with OSA, for 25.1 months in a study they conducted in 2007, and examined the dental and skeletal changes; they found no significant difference in mandibular length. There was a decrease in overbite and overjet. A statistically significant, clinically insignificant forward movement was observed in the mandibular incisors.

Bondemark [2] in 1999, applied splint therapy that positions the mandible in front (by $70 \%$ of its maximum protrusion; mean 5-8 $\mathrm{mm}$ and increased anterior vertical height by $5 \mathrm{~mm}$ ) on 30 patients with OSA with the average age of 55.3 (between 46.5 and 79.8) and measured by overlapping lateral cephalo- 
metric images taken at the start of treatment and 2 years later. It was observed that the lower jaw of the patients moved $0.4 \mathrm{~mm}$ anteriorly and rotated $0.3 \mathrm{~mm}$ clockwise. Despite these changes, there was no complaint in the patients. The researcher stated that this change may be due to remodelling or condylar position change in the condyle and/or glenoid fossa. Skeletal parameters were examined in this study. In our study, facial soft tissues were evaluated and the clockwise rotation of the lower jaw was found to be compatible with this study; contrary to this study, there was no difference in the sagittal position of the soft tissue pogonion and menton points before and after the treatment.

Robertson [25] applied splint therapy that positioned the mandible anteriorly to 100 patients with OSA and an average age of 49 , and followed it up for 30 months. The sagittal activation amount of the mandible was $75 \%$ of the maximum protrusion; observed changes in the vertical position of the condyle, total anterior and posterior face height in the first 6 months. He reported changes in the vertical position of the condyle in the total and lower face height at the $18^{\text {th }}$ month and found that the changes were stable at $24^{\text {th }}$ month. He emphasized that the decrease in overbite in the $30^{\text {th }}$ month was due to lower incisor proclination.

In 2009, Chan et al. [4] examined the lateral cephalometry images before and after treatment (6-8 weeks) by applying SomnoMed MAS to 69 patients with OSA, which positioned the mandible anterior$l y$, and reported an increase in lower anterior face height. In our study, our result of the increase in lower face height at a degree close to statistically significant is consistent with the results of the researchers $[2,4,25]$.

Considering the linear measurements made on the T0-T1 images, it was found that there was a statistically significant decrease in the mouth width 1 hour after the appliance was applied. When the T0-T2 and T0-T3 measurements are compared, it is seen that the decrease in the mouth width continues in a similar way, and a statistically significant difference was found when the two measurement differences are compared. The reason for the occurrence of this situation is the shrinkage in the width of the mouth with the movement of the soft tissues forward as a result of the lower jaw being brought forward with the device.
It was observed that the lower labiale point and crista philtri points were positioned statistically more anteriorly in the T0-T2 time interval. The difference occurred as a result of the lower jaw positioned in front. Considering the linear measurements between $\mathrm{T} 0-\mathrm{T} 2$, in contrast to the T0-T1 measurements, a decrease in nose width and an increase in nasal base width in addition to the change in mouth width were found to be statistically significant. In T0-T3 measurements, changes in nose width were found to be reversible; it was found that the change in the nasal base width continued. In this situation, as a result of the lower jaw moving forward as a result of the soft tissues associated with the lower jaw dragging the soft tissues in the upper anterior region relatively forward, the nose width decreased as a result of the stretching of the upper anterior region, while the nasal base expanded.

When looking at the results of the comparison of T0 and T3 values, it was seen that the changes in labiale inferius point and crista philtri points in the T0-T2 time interval were found to be reversible. A statistically significant difference was found at the soft tissue nasion point in the measurements in the TO-T3 period. This change made us think that it may have been caused by the adaptive movement of the soft tissue nasion point. When the linear measurements were examined, it was observed that there was a statistically significant decrease in the philtrum width between the T0 and T3 periods. No statistically significant change was found in any of the proportional and angular measurements, the changes mostly occurred in the mid and lower face region as a result of the lower jaw positioned in front and below.

\section{CONCLUSIONS}

Splint (SomnoMed MAS) treatment that positioned the mandible anteriorly did not make any difference in volumetric, proportional and angular measurements in the soft tissues of the face; It was observed that the changes in the lower and upper lip were reversible. It was thought that the decrease in mouth width and the increase in the base of the nose were caused by the stretching of the soft tissues as a result of the device that brought the lower jaw forward. The use of a device that positions the mandible anteriorly in patients who have completed their growth and development has created adaptive and 
compensatory changes in the lower facial soft tissues in the short term. We think that it will be beneficial to carry out new studies by keeping the follow-up period long in the future.

\section{Acknowledgements}

Thanks to Prof. Dr. Dr. Mehmet Irfan Karadede for his contribution to our work with his scientific experience.

\section{REFERENCES}

1. Arnett GW, Jelic JS, Kim J, et al. Soft tissue cephalometric analysis: diagnosis and treatment planning of dentofacial deformity. Am J Orthod Dentofacial Orthop. 1999; 116(3): 239-253, doi: 10.1016/s0889-5406(99)70234-9, indexed in Pubmed: 10474095.

2. Bondemark L. Does 2 years' nocturnal treatment with a mandibular advancement splint in adult patients with snoring and OSAS cause a change in the posture of the mandible? Am J Orthodont Dentofacial Orthopedics. 1999; 116(6): 621-628, doi: 10.1016/s08895406(99)70196-4.

3. Boulos MI, Jairam T, Kendzerska T, et al. Normal polysomnography parameters in healthy adults: a systematic review and meta-analysis. Lancet Respir Med. 2019; 7(6): 533-543, doi: 10.1016/S2213-2600(19)30057-8, indexed in Pubmed: 31006560.

4. Chan ASL, Sutherland K, Schwab RJ, et al. The effect of mandibular advancement on upper airway structure in obstructive sleep apnoea. Thorax. 2010; 65(8): 726-732, doi: 10.1136/thx.2009.131094, indexed in Pubmed: 20685749.

5. Chan ASL, Sutherland K, Cistulli PA. Mandibular advancement splints for the treatment of obstructive sleep apnea. Expert Rev Respir Med. 2020; 14(1): 81-88, doi: 10.1080/17476348.2020.1686978, indexed in Pubmed: 31663416.

6. Chan FC, Kawamoto HK, Federico C, et al. Soft-tissue volumetric changes following monobloc distraction procedure: analysis using digital three-dimensional photogrammetry system (3dMD). J Craniofac Surg. 2013; 24(2): 416-420, doi: 10.1097/SCS.0b013e31827ff296, indexed in Pubmed: 23524705.

7. Dattilo DJ. The mandibular trapezoid osteotomy for the treatment of obstructive sleep apnea: report of a case. J Oral Maxillofac Surg. 1998; 56(12): 1442-1446, doi: 10.1016/s0278-2391(98)90413-x, indexed in Pubmed: 9846544

8. Daurat A, Sarhane M, Tiberge M. [Obstructive sleep apnea syndrome and cognition: A review]. Neurophysiol Clin. 2016; 46(3): 201-215, doi: 10.1016/j.neucli.2016.04.002, indexed in Pubmed: 27321089.

9. Ferguson KA, Cartwright R, Rogers $\mathrm{R}$, et al. Oral appliances for snoring and obstructive sleep apnea: a review. Sleep. 2006; 29(2): 244-262, doi: 10.1093/sleep/29.2.244, indexed in Pubmed: 16494093.

10. Ferrario VF, Sforza C, Poggio CE, et al. Preliminary evaluation of an electromagnetic three-dimensional digitizer in facial anthropometry. Cleft Palate Craniofac J. 1998; 35(1): 9-15, doi: 10.1597/1545-1569_1998_035_0009_peoaet_2.3.co_2, indexed in Pubmed: 9482218.

11. Hammond RJ, Gotsopoulos H, Shen G, et al. A follow-up study of dental and skeletal changes associated with mandibular advancement splint use in obstructive sleep apnea. Am J Orthod Dentofacial Orthop. 2007; 132(6): 806-814, doi: 10.1016/j.ajodo.2005.08.047, indexed in Pubmed: 18068601.

12. Ilea A, Timuș D, Höpken J, et al. Oral appliance therapy in obstructive sleep apnea and snoring - systematic review and new directions of development. Cranio. 2019 [Epub ahead of print]: 1-12, doi: 10.1080/08869634.2019.1673285, indexed in Pubmed: 31588866.

13. Ivanhoe JR, Cibirka RM, Lefebvre CA, et al. Dental considerations in upper airway sleep disorders: A review of the literature. J Prosthet Dent. 1999; 82(6): 685-698, doi: 10.1016/s0022-3913(99)70010-7, indexed in Pubmed: 10588805.

14. Jen R, Orr JE, Li $Y$, et al. Accuracy of watchpat for the diagnosis of obstructive sleep apnea in patients with chronic obstructive pulmonary disease. COPD. 2020; 17(1): 34-39, doi: 10.1080/15412555.2019.1707789, indexed in Pubmed: 31965862.

15. Kapur VK, Auckley DH, Chowdhuri S, et al. Clinical practice guideline for diagnostic testing for adult obstructive sleep apnea: An American Academy of Sleep Medicine Clinical Practice Guideline. J Clin Sleep Med. 2017; 13(3): 479-504, doi: 10.5664/jcsm.6506, indexed in Pubmed: 28162150.

16. Kau CH, Richmond S, Incrapera A, et al. Three-dimensional surface acquisition systems for the study of facial morphology and their application to maxillofacial surgery. Int J Med Robot. 2007; 3(2): 97-110, doi: 10.1002/rcs.141, indexed in Pubmed: 17619242.

17. Lin SW, Sutherland K, Liao YF, et al. Three-dimensional photography for the evaluation of facial profiles in obstructive sleep apnoea. Respirology. 2018; 23(6): 618-625, doi: 10.1111/resp.13261, indexed in Pubmed: 29462843.

18. Lugaresi E, Plazzi G. Heavy snorer disease: from snoring to the sleep apnea syndrome--an overview. Respiration. 1997; 64 (Suppl 1): 11-14, doi: 10.1159/000196730, indexed in Pubmed: 9380955.

19. Lyons MF, Cameron DA, Banham SW. Snoring, sleep apnoea and the role of dental appliances. Dent Update. 2001; 28(5): 254-256, doi: 10.12968/denu.2001.28.5.254, indexed in Pubmed: 11490637.

20. Maal TJJ, Verhamme LM, van Loon B, et al. Variation of the face in rest using 3D stereophotogrammetry. Int J Oral Maxillofac Surg. 2011; 40(11): 1252-1257, doi: 10.1016/j. ijom.2011.02.033, indexed in Pubmed: 21514117.

21. Maspero C, Giannini L, Galbiati G, et al. Obstructive sleep apnea syndrome: a literature review. Minerva Stomatol. 2015; 64(2): 97-109, indexed in Pubmed: 25747430.

22. Metzger TE, Kula KS, Eckert GJ, et al. Orthodontic soft-tissue parameters: a comparison of cone-beam computed tomography and the 3dMD imaging system. Am J Orthod Dentofacial Orthop. 2013; 144(5): 672-681, doi: 10.1016/j.ajodo.2013.07.007, indexed in Pubmed: 24182583. 
23. Osman AM, Carter SG, Carberry JC, et al. Obstructive sleep apnea: current perspectives. Nat Sci Sleep. 2018; 10: 21-34, doi: 10.2147/NSS.S124657, indexed in Pubmed: 29416383.

24. Ramar K, Dort LC, Katz SG, et al. Clinical practice guideline for the treatment of obstructive sleep apnea and snoring with oral appliance therapy: an update for 2015. J Clin Sleep Med. 2015; 11(7): 773-827, doi: 10.5664/jcsm.4858, indexed in Pubmed: 26094920.

25. Robertson CJ. Dental and skeletal changes associated with long-term mandibular advancement. Sleep. 2001; 24(5): 531-537, doi: 10.1093/sleep/24.5.531, indexed in Pubmed: 11480650.

26. Sawyer AR, See M, Nduka C. 3D stereophotogrammetry quantitative lip analysis. Aesthetic Plast Surg. 2009; 33(4): 497-504, doi: 10.1007/s00266-008-9191-1, indexed in Pubmed: 18584237.

27. Silva MA, Wolf U, Heinicke F, et al. Cone-beam computed tomography for routine orthodontic treatment planning: a radiation dose evaluation. Am J Orthod Dentofacial Orthop. 2008; 133(5): 640.e1-640.e5, doi: 10.1016/j. ajodo.2007.11.019, indexed in Pubmed: 18456133.
28. Sullivan CE, Issa FG, Berthon-Jones M, et al. Reversal of obstructive sleep apnoea by continuous positive airway pressure applied through the nares. Lancet. 1981; 1(8225): 862-865, doi: 10.1016/s0140-6736(81)92140-1, indexed in Pubmed: 6112294.

29. Taylor HO, Morrison CS, Linden O, et al. Quantitative facial asymmetry: using three-dimensional photogrammetry to measure baseline facial surface symmetry. J Craniofac Surg. 2014; 25(1): 124-128, doi: 10.1097/SCS.0b013e3182a2e99d, indexed in Pubmed: 24406564.

30. Veasey SC, Rosen IM, Veasey SC, et al. Obstructive sleep apnea in adults. $N$ Engl J Med. 2019; 380(15): 1442-1449, doi: 10.1056/NEJMcp1816152, indexed in Pubmed: 30970189.

31. Wong JY, Oh AK, Ohta E, et al. Validity and reliability of craniofacial anthropometric measurement of 3D digital photogrammetric images. Cleft Palate Craniofac J. 2008; 45(3): 232-239, doi: 10.1597/06-175, indexed in Pubmed: 18452351.

32. Yoshida K. Oral device therapy for the upper airway resistance syndrome patient. J Prosthet Dent. 2002; 87(4): 427-430, doi: $10.1067 / \mathrm{mpr} .2002 .123228$, indexed in Pubmed: 12011859. 